\title{
A COMPARISON OF IDU SOLUTION, IDU OINTMENT, AND CARBOLIZATION IN THE TREATMENT OF DENDRITIC CORNEAL ULCER*
}

\author{
BY \\ A. D. MACKENZIE \\ Department of Ophthalmology, Royal Eye Hospital, Manchester
}

5-IODO-2-'DEOXYURIDINE (IDU) was first shown to be effective in the treatment of human herpes simplex keratitis by Kaufman, Martola, and Dohlman (1962). In Great Britain reports have been conflicting, for Corrigan, Gilkes, and Roberts (1962) obtained success in all of fifteen cases, whereas Davidson (1962) and Luntz and MacCallum (1963) were less enthusiastic.

Patterson and others (1963) showed, by means of a blind trial, that IDU had a beneficial action, results with IDU being statistically better than those with "control" drops.

Hitherto, most of the clinical work has been done with IDU in saturated solution, the maximum concentration being only 0.1 per cent. It was therefore decided to compare the action of IDU in ointment form (using a concentration of 0.5 per cent.) with that of the saturated solution and with the established treatment by chemical debridement of the epithelium using carbolic acid.

In addition it was thought necessary to compare these results in both in-patients and out-patients.

\section{Material and Methods}

Eighty eyes with typical dendritic keratitis were seen in the Out-patients Department of Manchester Royal Eye Hospital. Every patient was seen daily while the condition remained active, 37 eyes being treated in the out-patients department and 43 in hospital.

The eighty eyes were divided into three groups:

(1) 25 were treated with IDU solution $(0 \cdot 1$ per cent.) instilled hourly throughout the day, and in the case of in-patients 2 -hrly by night.

(2) 28 were treated with IDU ointment ( 0.5 per cent.) instilled 4-hrly in in-patients, and at four evenly-spaced intervals throughout the day, in out-patients.

(3) 27 were treated by carbolization of the staining area followed by local chemotherapy.

IDU solution was prepared by dissolving IDU powder $\dagger$ in distilled water and adding phenyl mercuric nitrate as preservative. The base used for the ointment was Liq. Paraff. 20 per cent. and Paraff. Mol. ad 100 per cent.

In all cases a mydriatic was instilled while the condition remained active.

The eyes treated with IDU which either showed no response, or in which an initial favourable response had become static after a reasonable period (4 or 5 days) were then carbolized and treated with local chemotherapy instead of IDU. In such cases it was not considered to be in the patient's interest to persist with the IDU therapy.

* Received for publication September 3, 1963.

$\dagger$ "Kerecid" powder (Smith Kline and French Laboratories Ltd.). 


\section{Assessment of Cure}

The criterion was the disappearance of staining with 2 per cent. fluorescein as observed with the corneal loupe.

In order to compare the severity of the cases in each group, the size of the initial active lesions as revealed by fluorescein was graded from 1 to 7 as follows:

1. The smallest lesion recognizable as dendritic in shape (the pin-point stellate lesion).

2. Larger than (1) but less than $3 \mathrm{~mm}$. in length.

3. Larger than (2) but involving less than $\frac{1}{16}$ of the corneal surface area.

4. Involving from $\frac{1}{16}$ th to $\frac{1}{8}$ th of the corneal surface area.

5. Involving from $\frac{1}{8}$ th to $\frac{1}{4}$ of the corneal surface area.

6. Involving from $\frac{1}{4}$ to $\frac{1}{2}$ of the corneal surface area.

7. Involving more than $\frac{1}{2}$ of the corneal surface area.

To facilitate this clinical assessment a standard diagram was used showing the corneal proportions referred to above. The grading was done objectively, without knowing which treatment the eye was going to have.

\section{Results}

These are summarized in the Table.

TABLE

\begin{tabular}{|c|c|c|c|c|c|c|c|c|c|c|c|c|}
\hline & $\begin{array}{l}\text { thod of } \\
\text { atment }\end{array}$ & $\begin{array}{l}\text { In-patient } \\
\text { or } \\
\text { Out-patient }\end{array}$ & $\begin{array}{l}\text { Number } \\
\text { of Cases } \\
\text { Treated }\end{array}$ & $\begin{array}{c}\text { Average } \\
\text { Grade } \\
\text { of } \\
\text { Severity }\end{array}$ & $\begin{array}{c}\text { Number } \\
\text { Cured }\end{array}$ & $\begin{array}{l}\text { Per- } \\
\text { centage } \\
\text { Cured }\end{array}$ & $\begin{array}{l}\text { Number } \\
\text { Not } \\
\text { Cured }\end{array}$ & $\begin{array}{c}\text { Time } \\
\text { for Cure } \\
\text { to Occur } \\
\text { (days) }\end{array}$ & $\begin{array}{l}\text { Average } \\
\text { Time } \\
\text { (days) }\end{array}$ & $\begin{array}{l}\text { Number } \\
\text { Sub- } \\
\text { sequently } \\
\text { Recur- } \\
\text { ring }\end{array}$ & $\begin{array}{c}\text { Side- } \\
\text { effects }\end{array}$ & $\begin{array}{c}\text { Average } \\
\text { Duration } \\
\text { of } \\
\text { Follow-up }\end{array}$ \\
\hline & & & & & 2 & 29 & & 4-6 & 5 & 0 & NU & - \\
\hline & Solution & & 1 & 2.1 & & & $5^{*}$ & & & 2 & NII & 9 \\
\hline & per cent. & $\mathbf{P}$ & 18 & 2.55 & 9 & 50 & & 4-9 & $6 \cdot 2$ & 1 & One & 9 \\
\hline IDU & & $1-\mathrm{T}$ & 10 & 2.03 & & & $9^{*}$ & & & 3 & & 3 \\
\hline $1 \mathrm{D}$ & & $\mathrm{P}$ & 15 & 2.00 & 9 & 60 & & $5-9$ & $6 \cdot 3$ & $0 \mp$ & Three & $?$ \\
\hline & Ointment & $1-\mathrm{r}$ & 10 & 230 & & & $6^{*}$ & & & $0 \ddagger$ & & 2 \\
\hline & per cent. & D & 13 & 200 & 9 & 69 & & $3-19$ & 8.0 & $0 \ddagger$ & One & 3 \\
\hline & & $U-T$ & 13 & 500 & & & $4^{*}$ & & & $0 \ddagger$ & & 3 \\
\hline & & $\mathbf{P}$ & 10 & 2.60 & 9 & 90 & & $4-14$ & $8 \cdot 0$ & 1 & One & 7 \\
\hline Carbc & ization & $1-1$ & 10 & 200 & & & $1 \dagger$ & & & & & 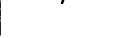 \\
\hline Chem & therapy & 8 & 17 & 2,1 & 17 & 100 & & $1-18$ & $8 \cdot 0$ & 2 & Two & 7 \\
\hline & & $0-1$ & 17 & 270 & & & 0 & & & & & 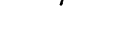 \\
\hline
\end{tabular}

* Subsequently carbolized. † Required tarsorrhaphy. $\ddagger$ Period of follow-up too short to indicate recurrence rate.

\section{Discussion}

Even allowing for the fact that the average severity of the cases treated by carbolization was slightly less than that of those treated with IDU ointment or solution, it seems that IDU is a less reliable cure for dendritic ulcer than carbolization. 
The higher concentration afforded by the use of an ointment vehicle gives better results than the saturated solution of IDU. This is particularly evident in the outpatients, 69 per cent. of those using the ointment being cured compared with 29 per cent. of those using the solution. As the latter requires hourly instillation, it seems that the out-patients using it did not receive regular or adequate treatment. The ointment requires only 4-hrly application and is thus a more practicable method of therapy, as well as being more efficient.

Superficial punctate keratitis occurred in five of the 53 patients treated with IDU, and rapidly resolved in each case on stopping the treatment. It is possible that this was a side-effect of IDU therapy, but it was also noted in three of the 27 cases treated by carbolization.

No harmful side-effects followed the use of IDU, nor did the size of the ulcerated area increase. In many cases, particularly those with large geographic ulcers, there was an initial improvement with IDU as shown by reduction in size of the staining area, often to a pinpoint. At this stage the condition remained static, and carbolization was carried out. It was then sufficient to carbolize a much smaller area of cornea than would otherwise have been necessary.

It was not possible to compare accurately the degree of stromal involvement after IDU therapy with that after carbolization, but the overall impression was that there was no difference.

\section{Summary}

Eighty eyes with typical dendritic ulcer of the cornea were treated by one of three methods: IDU solution $(0 \cdot 1$ per cent.); IDU ointment $(0 \cdot 5$ per cent.); carbolization. The best results were achieved with carbolization. IDU ointment appears to be more effective than the solution especially among out-patients, and it requires much less frequent instillation.

I should like to thank Mr. O. M. Duthie and Mr. R. Dalgleish of the University of Manchester, Department of Ophthalmology, for allowing me to treat patients under their care, permission to use their in-patient facilities, and guidance in the preparation of this paper.

I also wish to thank Mr. P. L. Blaxter, Mr. F. Janus, and Mr. S. B. Smith for permitting me to treat some of their patients.

I am indebted to Smith Kline and French Laboratories Ltd., particularly Dr. J. Johnston, for the supply of "Kerecid" powder and solution.

\section{REFERENCES}

Corrigan, M. J., Gilkes, M. J., and Roberts, D. St. Clair (1962). Brit. med. J., 2, 304.

DAVIDSON, S. I. (1962). Lancet, 2, 1326.

Kaufman, H. E., Martola, E., and Dohlman, C. (1962). Arch. Ophthal. (Chicago), 68, 235.

LunTZ, M. H., and MacCallum, F. O. (1963). Brit. J. Ophthal., 47, 449.

PatTerson, A., and eight others (1963). Trans. ophthal. Soc. U.K., 83, 583. 